\title{
PERENCANAAN PENANGKAL PETIR DI GEDUNG SEKOLAH TINGGI TEKNOLOGI PEKANBARU
}

\author{
Ermawati ${ }^{1,}$ Engla Harda Arya ${ }^{2}$ \\ STT Pekanbaru \\ Jl. Dirgantara No.4, Kel, Sidomulyo Tim., Kec. Marpoyan Damai, Kota Pekanbaru, Riau 28125 \\ Email:ermawatip44@gmail.com ${ }^{1}$,Englahardaarya@gmail.com ${ }^{2}$
}

\begin{abstract}
The installation of lightning rods is very necessary for office buildings, buildings, towers so that humans and equipment inside the building are protected from the danger of lightning strikes. This study plans a good lightning rod to be installed in the Pekanbaru Technology High School building by knowing the values of lightning strike density, lightning strike distance, the level of building hazard estimates, determining the area that attracts lightning strikes, determining the number of lightning strikes per year, and determining the radius. protection against lightning strikes. The results of the research that has been carried out, in the Pekanbaru Technological School (STTP) building with a building length of $32.50 \mathrm{~m}$, a building width of $22.50 \mathrm{~m}$, and a building height of $18.00 \mathrm{~m}$. obtained the value of lightning density $N_{-} g=35,3602 \mathrm{~km}^{2} / y e a r$, area of attraction for lightning strikes $A \_e=15,827.49 \mathrm{~m}^{2}$, the number of lightning strikes $N \_d=0,559 / y e a r$, has level III protection with $E=082$, area of radius $A \_x=174.885 .44$ $\mathrm{m}^{2}$, So to be safer from lightning strikes, the STTP building using an electrostatic lightning rod is enough to use 1 finial with a length of $2 \mathrm{~m}$.
\end{abstract}

Keywords: electrostatic, lightning rod, lightning strike, strike density,

\section{Abstrak (Times New Roman 10 Bold)}

Pemasangan penangkal petir sangat diperlukan untuk bangunan kantor, gedung, menara agar manusia dan peralatan-peralatan yang berada didalam bagunan tersebut terhindar dari bahaya sambaran petir. Penelitian ini merencanakan penangkal petir yang baik untuk dipasang di gedung Sekolah Tinggi Teknologi Pekanbaru dengan mengetahui nilai-nilai kerapatan sambaran petir, jarak sambaran petir, tingkat perkiraan bahaya bangunan, menentukan luas daerah yang menarik sambaran petir, menentukan jumlah sambaran petir pertahun, dan menentukan radius perlindungan terhadap sambaran petir. Hasil penelitian yang telah dilakukan, pada gedung Sekolah Tinggi Teknologi Pekanbaru (STTP) dengan panjang bangunan $32,50 \mathrm{~m}$, lebar bangunan $22,50 \mathrm{~m}$, dan tinggi bangunan $18,00 \mathrm{~m}$. didapatkan nilai kerapatan petir $\mathrm{N}_{\mathrm{g}}=35.3602 \mathrm{~km}^{2} /$ tahun, luas daerah menarik sambaran petir $\mathrm{A}_{\mathrm{e}}=15.827,49 \mathrm{~m}^{2}$, jumlah sambaran petir $\mathrm{N}_{\mathrm{d}}=0,559 /$ tahun, memiliki proteksi tingkat III dengan $\mathrm{E}=082$, luas radius $\mathrm{A}_{\mathrm{x}}=174.885,44$ $\mathrm{m}^{2}$, Maka untuk lebih aman dari sambaran petir maka gedung STTP menggunakan penangkal petir elektrostatik cukup menggunakan 1 finial dengan panjangnya $2 \mathrm{~m}$.

Kata kunci: elektrostatis, penangkal petir,sambaran petir, kerapatan sambaran

\section{Pendahuluan}

Petir merupakan peristiwa peluahan listrik antara suatu awan bermuatan dengan bumi, atau antara awan bermuatan dengan awan bermuatan lainnya. Dalam peristiwa ini, jarak antara awan ke awan atau awan ke bumi relative cukup tinggi dan dapat diasumsikan sebagai jarak elektroda. sumber terjadinya petir adalah awan cummulonimbus atau awan guruh yang 
berbentuk gumpalan dengan ukuran vertical lebih besar dari ukuran horizontal. Ukuran vertical dapat mencapai $14 \mathrm{~km}$ dan ukuran horizontal berkisar 1,5 sampai 7,5 km [1].

Perencanaan penangkal petir adalah untuk memperoleh suatu sistem yang direncanakan dan dilaksanakan dengan baik sehingga jika terjadi sambaran petir maka sarana inilah yang menyalurkan arus petir ke dalam tanah dengan aman tanpa menimbulkan bahaya bagi makhluk hidup dan benda lainnya yang berada di dalam, di luar atau di sekitar bangunan. Bagian bangunan yang biasanya terkena sambaran petir adalah ujung-ujung runcing dari atap, bumbungan, jurai atau lisplang-atap, puncak menara, cerobong asap atau bangunan yang menonjol di atap. Petir yang terjadi antara awan dengan permukaan bumi dapat menimbulkan kerusakan pada gedung tinggi dan peralatannya [2].

Pembangunan gedung Sekolah Tinggi Teknologi Pekanbaru (STTP) yang terdiri dari 4 lantai sangat membutuhkan instalasi penangkal petir yang baik dikarenakan bangunan bertingkat lebih memiki resiko gangguan sambaran petir, baik gangguan mekanik maupun gangguan alam. Salah satu gangguan alam yang sering terjadi adalah sambaran petir. Mengingat letak geografis Indonesia yang dilalui garis khatulistiwa menyebabkan Indonesia beriklim tropis, akibatnya Indonesia memiliki hari guruh rata-rata per tahun yang sangat tinggi. Akibat terkena sambaran petir dapat membahayakan makhluk hidup dan peralatan listrik yang ada di dalam gedung tersebut. Untuk melindungi dan mengurangi dampak kerusakan akibat sambaran petir maka di gedung tersebut perlu dipasang instalasi penangkal petir.

Teknik penangkal petir ini yang sederhana dan pertama kali dikenal menggunakan prinsip yang pertama, yaitu dengan membentuk semacam tameng atau perisai berupa konduktor yang akan mengambil alih sambaran petir. Sistem proteksi konvensional memiliki tiga bagian utama yaitu batang penangkal petir, kabel konduktor serta tempat pembumian. Batang penangkal petir atau terminasi udara sering juga disebut splitzer berada paling atas gedung atau menara [3].
Finial ialah penangkal petir batang pendek yang biasa dipasang pada bangunan atap datar yang mempergunakan instalasi penangkal petir sistem kurungan faraday sedangkan bangunan atap runcing mempergunakan metode Rolling Sphere, metode sudut proteksi dan metode jala.

Finial berupa konduktor batang tegak merupakan finial yang memiliki konstruksi berupa sisi ujung finialnya secara umum berbentuk metal yang runcing sebagai pengumpul muatan listrik statis dan diletakkan pada tempat yang tinggi khususnya pada atap bangunan miring, sehingga petir diharapkan menyambar ujung metal tersebut terlebih dahulu [4].

Penelitian lainnya yang dilakukan oleh [5] yang berjudul "Perancangan Kinerja Penangkal Petir Menggunakan Metoda Bola Gelinding pada Gedung Perpustakaan Universitas Lancang Kuning Pekanbaru". Petir merupakan gejala alam dan tidak bisa dihilangkan atau dicegah, kejadian petir dapat melibatkan arus impuls yang tinggi, dalam waktu singkat dengan akibat bahaya yang besar. Pelepasan muatan listrik antara awan dengan tanah terjadi karena adanya kuat medan listrik antara muatan di awan dengan muatan induksi di permukaan tanah. Semakin besar muatan yang terdapat di awan, semakin besar pula medan listrik yang terjadi. Apabila kuat medan ini melebihi kuat medan tembus udara, maka akan terjadi pelepasan muatan peristiwa pelepasan muatan ini dinamakan kilat atau petir.

Mengingat kota pekanbaru termasuk daerah dengan sambaran petir yang cukup tinggi, apakah perlu penangkal petir dipasang pada Gedung Sekolah Tinggi Teknologi Pekanbaru. Jenis penangkal petir apakah yang cocok dipasang pada Gedung sekolah tinggi teknologi pekanbaru.

\section{Methodologi}

Penelitian ini bertujuan untuk merencanakan suatu sistem instalasi penangkal petir yang sesuai untuk dipasang pada gedung Sekolah Tinggi Teknologi Pekanbaru (STTP), sehingga gedung tersebut benar-benar dapat terlindungi dari bahaya sambaran petir. 
Langkah-langkah yang digunakan dalam perencanaan adalah sebagai berikut:

\subsection{Prosedur}

Dalam melakukan pengumpulan datadata penulis melalui beberapa prosedur, diantaranya adalah:

1. Melakukan observasi lapangan ke Dinas Pekerjaan Umum Kota Pekanbaru (PU) dan Badan Meteorologi Klimatologi dan Geofisika Stadiun Klimatologi Pekanbaru (BMKG).

2. Melakukan observasi ke gedung Sekolah Tinggi Teknologi Pekanbaru.

\subsection{Objek Perencanaan}

Objek dalam penelitian ini adalah gedung Sekolah Tinggi Teknologi Pekanbaru dengan berukuran $32,50 \mathrm{~m}$ x $16 \mathrm{~m}$ yang terletak di jalan Dirgantara No. 04 Kota Pekanbaru, Riau.

\subsection{Metode Pengumpulan Data}

Metode pengumpulan data yang diambil dalam penelitian ini adalah metode observasi dan studi kepustakaan.

\subsection{Teknik Analisis Data}

Data yang diperoleh akan dianalisis. Langkah-langkah perencanaan instalasi penangkal petir yang dilakukan adalah :

1. Menentukan tingkat perkiraan bahaya gedung STTP

$$
R=A+B+C+D+E
$$

2. Menentukan kerapatan sambaran petir

$$
N_{g}=0,04 \cdot T_{d}{ }^{1,25} \mathrm{~km}^{2} / \text { tahun }
$$

3. Menentukan luas daerah yang menarik sambaran petir

$$
A_{e}=a b+6 h(a+b)+9 \pi h^{2}
$$

4. Menentukan jumlah sambaran petir per tahun

$$
N_{d}=N_{g} \cdot A_{e^{*}} 10^{-6} / \text { tahun }
$$

5. Menentukan tingkat proteksi

$$
E=1-\frac{N_{c}}{N_{d i}}
$$

6. Menentukan jarak sambaran petir $r=8,0 \cdot I_{\max }{ }^{0,6 i}$ (meter)

7. Menentukan luas daerah proteksi (Rolling Sphere)

$$
A_{x}=\pi \cdot(R)^{2}
$$

8. Menentukan sudut lindung

$$
a=\sin ^{-1}\left[1-\left(\frac{h}{r}\right)\right]
$$

9. Menentukan jumlah elektroda

$$
\text { Penyalur petir tambahan }=\frac{\text { luas area }}{\text { luas daerah proteksi }}
$$

10. Menentukan menentukan luas daerah proteksi (Elektrostatik)

$$
A_{x}=\pi \cdot r^{2}
$$

11. Menentukan radius proteksi (Elektrostatik)

$$
R_{p}=\sqrt{2 r h-h^{2}+\Delta(2 D+\Delta}
$$

12. Menentukan luas daerah proteksi standar NFC 17-102 (Elektrostatik) $A_{x}=\pi \cdot R_{p}^{2}$

13. Menentukan terminasi udara

14. Menentukan konduktor penyalur

15. Perbandingan sistem penangkal petir Rolling Sphere dan Elektrostatik

\section{Hasil dan Pembahasan}

\subsection{Deskripsi Bangunan}

Gedung Sekolah Tinggi Teknologi Pekanbaru (STTP) yang terletak di Jl. Dirgantara No.4 Kota Pekanbaru. Gedung ini dibangun diatas lahan seluas $731,25 \mathrm{~m}^{2}$. Data dimensi gedung Sekolah Tinggi Teknologi Pekanbaru (STTP) sebagai berikut :

1.

2.

3.

$22,50 \mathrm{~m}$

Panjang bangunan

$$
=32,50 \mathrm{~m}
$$

Lebar bangunan =

$$
\text { Tinggi bangunan }
$$$$
=18,00 \mathrm{~m}
$$

Dari data-data yang diatas kita dapat menentukan tingkat perkiraan bahaya gedung STTP $(\mathrm{R})=\mathrm{A}+\mathrm{B}+\mathrm{C}+\mathrm{D}+\mathrm{E}$ dengan indeks-indeks sebagai berikut dengan menggunakan persamaan (5) :

1. Indeks A penggunaan dan isi

Gedung STTP merupakan gedung yang berisi cukup banyak orang dan banyak barang-barang berharga dan berisi arsip dan dokumen penting.

Nilai $=2$

2. Indeks B kontruksi bangunan

Gedung STTP termasuk bangunan dengan menggunakan kontruksi beton bertulang.

Nilai $=2$

3. Indeks $\mathrm{C}$ tinggi bangunan

Gedung STTP mempunyai ketinggian 18,00 meter

Nilai $=4$ 
4. Indeks D situasi bangunan

Gedung STTP terletak di tanah datar pada semua kegiatan

Nilai $=0$

5. Indeks E pengaruh kilat

Hari guruh pertahun di daerah Riau adalah 218

Nilai $=7$

Jadi Jumlah $\mathrm{R}=\mathrm{A}+\mathrm{B}+\mathrm{C}+\mathrm{D}+\mathrm{E}$

$$
\mathrm{R}=2+2+4+0+7=15
$$

Karena nilai $\mathrm{R}=15$ maka indeks perkiraan bahaya terhadap sambaran petir pada gedung STTP adalah sangat besar. Sehingga pengaman untuk gedung STTP terhadap sambaran petir sangat dianjurkan.

\subsection{Menentukan Kerapatan Sambaran Petir}

Adapun beberapa data kota - pulau hari guruh dari BMKG pada tahun 2018.

Tabel 3.1 BMKG Hari Guruh per Tahun 2018

\begin{tabular}{|c|c|c|c|}
\hline No & Kota - Pulau & $\begin{array}{c}\text { Curah } \\
\text { Petir }\end{array}$ & IKL \\
\hline 1 & Bogor - Jawa & 201 & 55.15 \\
\hline 2 & $\begin{array}{c}\text { Belawan - } \\
\text { Sumatera }\end{array}$ & 246 & 67.36 \\
\hline 3 & $\begin{array}{c}\text { Balikpapan - } \\
\text { Kalimantan }\end{array}$ & 227 & 62.10 \\
\hline 4 & Citeko - Jawa & 227 & 62.30 \\
\hline 5 & Gorontalo - & 212 & 58.08 \\
\hline 6 & Indramayu - Jawa & 187 & 51.23 \\
\hline 7 & Jakarta - Jawa & 193 & 52.88 \\
\hline 8 & Jaya Pura - Irian & 197 & 53.88 \\
\hline 9 & Banyuwangi-Jawa & 101 & 27.56 \\
\hline
\end{tabular}

\begin{tabular}{|c|c|c|c|}
\hline 10 & $\begin{array}{l}\text { Meulaboh - } \\
\text { Sumatera }\end{array}$ & 178 & 48.77 \\
\hline 11 & Lhokseumawe & 201 & 55.07 \\
\hline 12 & Medan - Sumatera & 224 & 61.34 \\
\hline 13 & $\begin{array}{l}\text { Sibolga - } \\
\text { Sumatera }\end{array}$ & 158 & 43.29 \\
\hline 14 & Dumai - Sumatera & 218 & 59.75 \\
\hline 15 & Riau - Sumatera & 218 & 59.33 \\
\hline 16 & $\begin{array}{c}\text { Pangkal Pinang - } \\
\text { Kalimantan }\end{array}$ & 118 & 32.33 \\
\hline 17 & $\begin{array}{c}\text { Paloh - } \\
\text { Kalimantan }\end{array}$ & 188 & 51.56 \\
\hline 18 & Batam - Batam & 131 & 35.94 \\
\hline 19 & Amahai - Maluku & 109 & 29.95 \\
\hline 20 & $\begin{array}{c}\text { Masamba - } \\
\text { Sulawesi }\end{array}$ & 248 & 67.88 \\
\hline
\end{tabular}

Kerapatan sambaran petir dapat diketahui dengan persamaan (3)

$$
\begin{aligned}
N_{g} & =0,04 \cdot T d^{1,26} \mathrm{~km}^{2} / \text { tahun } \\
N_{g} & =0,04 \cdot 218^{1,26} \\
& =35.3602 \mathrm{~km}^{2} / \text { tahun }
\end{aligned}
$$

Dimana :

$\mathrm{Td}=$ hari guruh per tahun

Nilai $N_{g}$ digunakan untuk menentukan jumlah sambaran petir per tahun pada sub bab berikutnya.

\subsection{Menentukan Luas Daerah yang Menarik Sambaran Petir Luas}

Area ekivalen pada gedung STTP dapat dicari menggunakan persamaan (12), yaitu :

$A_{e}=a b+6 h(a+b)+9 \pi h^{2}$ 
$=32,50.22,50+6.18(32,50+22,50)+$

$9.3,14 \cdot 18^{2}$

$$
=15.827,49 \mathrm{~m}^{2}
$$

Dimana :

$$
\begin{aligned}
& \mathrm{a}=\text { panjang bangunan } \\
& \mathrm{b}=\text { lebar bangunan } \\
& \mathrm{h}=\text { tinggi bangunan }
\end{aligned}
$$

Hasil luas daerah yang menarik sambaran petir pada gedung STTP bernilai $15.827,49 \mathrm{~m}^{2}$. Dan $A_{e}$ tersebut digunakan untuk menentukan jumlah sambaran petir per tahun.

\subsection{Menentukan Jumlah Sambaran Petir per Tahun}

Jumlah rata-rata frekuensi sambaran petir langsung per tahun $\left(N_{d}\right)$ diketahui persamaan (13), yaitu :

$$
\begin{aligned}
N_{d} & =N_{g} \cdot A_{e} \cdot 10^{-6} \\
& =35.3602 \cdot 15.827,49 \cdot 10^{-6} \\
& =0.559 / \text { tahum }
\end{aligned}
$$

Diamana :

$$
N_{d}=\text { Frekuensi sambaran petir per }
$$
tahun

$N_{g}=$ Kerapatan sambaran petir

$A_{e}=$ Luas area ekivalen

Jumlah rata-rata frekuensi sambaran petir langsung bernilai $N_{d}=0.559 / \operatorname{tahun}$

3.5. Menentukan Efesiensi Sistem Proteksi Petir (SPP) lalu Menentukan Tingkat Proteksi

Dari stasiun BMKG diperoleh nilai frekuensi sambaran petir tahunan setempat $\left(N_{c}\right)$ yang diperbolehkan adalah $10^{-1} /$ tahun. Nilai $\quad N_{d}>N_{c}$ maka diperlukan sistem proteksi dan efesiensi SPP dapat dihitung berdasarkan persamaan (14), yaitu :

$$
\begin{aligned}
& E=1-\frac{N_{c}}{N_{d}} \\
& E=1-\frac{0,1}{0.559}
\end{aligned}
$$

$$
E=0.821
$$

Dimana :

$$
\begin{aligned}
& N_{d}=\text { Frekuensi sambaran petir per tahun } \\
& N_{c}=\text { Frekuensi sambaran petir setempat }
\end{aligned}
$$

Berdasarkan hasil perhitungan $E$ didapatkan nilai $E=0,821$, nilai $E$ ini mendekati 0,90 dengan $E$ ini dapat ditentukan tingkat proteksi untuk gedung STTP, Maka didapatkan bahwa gedung STTP mempeunyai tingkat proteksi III. Maka dapat ditentukan sudut proteksinya $\left(\alpha^{\circ}\right)$ dari penempatan suatu terminal udara, radius bola yang di pakai maupun jala (konduktor horizontal) sesuai tabel 3.2.

Tabel 3.2. Daerah Proteksi dari Teriminasi Udara sesuai dengan Tingkat Proteksinya

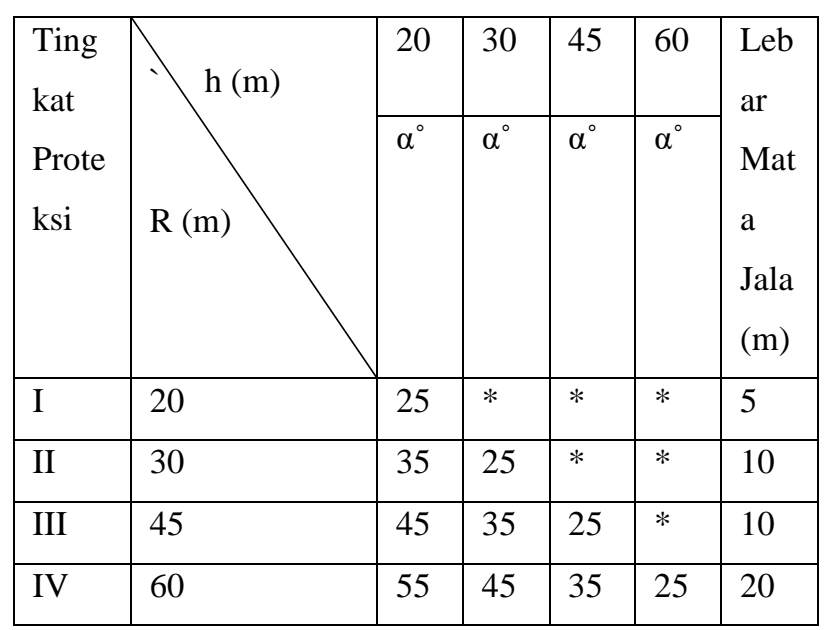

\subsection{Menentukan Radius Perlidungan Terhadap Sambaran Petir \\ Adapun untuk radius perlindungan terhadap sambaran petir penulis akan menggunakan metode Elektrostatik sebagai berikut}

Pada sistem penangkal petir elektrostatik yang direncanakan akan dipasang diatap gedung STTP dengan jenis Helita Pulsar 60 No tipe IMH. 6012 dengan panjang terminasi udara 2 meter.

Radius penangkal petir bila yang direncanakam 87,989 meter maka penulis menggunakan radius 100 meter pada sistem ini. Karena pada acuan standar desain pabrikan radius yang tertera adalah 100 meter sampai 150

SURYA TEKNIKA Vol. 8 No. 2, Desember 2021: 320-326 
meter lebih maka luas daerah proteksinya berdasarkan persamaan (1), yaitu :

$$
\begin{aligned}
& A_{x}=\pi \cdot r^{2} \\
& A_{x}=3,14.100^{2} \\
& A_{x}=31.400 \mathrm{~m}^{2}
\end{aligned}
$$

Bangunan gedung STTP memiliki tingkat proteksi tingkat III berhubung dengan sistem penangkal petir elektrostatik proteksi tingkat III yaitu dengan D sebesar $45 \mathrm{~m}$, berdasarkan spesifikasi pulsar nilai $\Delta \quad 60$. Berdasarkan persamaan (3), yaitu :

$$
\begin{aligned}
& R p=\sqrt{2 r h-h^{2}+\Delta(2 \mathrm{D}+\Delta)} \\
& R p=\sqrt{2.45 .11-11^{2}+60(2.45+60)} \\
& R p=\sqrt{55830} \\
& R p=236 \text { meter }
\end{aligned}
$$

Dimana: $\quad: \mathrm{h}=$ (bangunan tertinggi bangunan terendah - jarak atap dari bawah support final) + tinggi support terminasi udara

$$
\begin{aligned}
& \mathrm{h}=(18-7-2)+2=11 \\
& \mathrm{D}=45 \mathrm{~m} \\
& : \Delta=60 \mathrm{~m}
\end{aligned}
$$

Bila merujuk pada spesifikasi yang tertulis penangkal petir yang terpasang mempunyai radius proteksi sebesar 87,989 m, namun pada kenyataan berdasarkan perhitungan menggunakan standar NFC 17-102 diatas hanya sekitar $236 \mathrm{~m}$ sehingga luas radius proteksinya menjadi :

$$
\begin{aligned}
& A_{x}=\pi \cdot R_{\mathrm{p}}{ }^{2} \\
& A_{x}=3,14.236^{2} \\
& A_{x}=174.885,44 \mathrm{~m}^{2}
\end{aligned}
$$

Berdasarkan spesifikasi penangkal petir tersebut memiliki radius proteksi $100 \mathrm{~m}$ dan luas proteksinya $31.400 \mathrm{~m}^{2}$ namun berdasarkan analisa perhitungan menggunakan standar NFC 17-102 radius proteksi sebesar $236 \mathrm{~m}$ dengan luas radius sebesar $174.885,44 \mathrm{~m}^{2}$ sehingga terjadi kenaikan radius karena adanya perhitungan bangunan terendah sekitar lokasi.
Dari perhitungan di atas bahwa jenis penagkal petir Elektrostatik mempeunyai luas radius sebesar $174.885,44 \mathrm{~m}^{2}$. semsntara luas area gedung STTP adalah sebesar 731,25 2 , maka digunakan jenis penangkal petir Elektrostatik karena luas radius penangkal petir ini mampu melindungi seluruh area gedung STTP terhadap sambaran petir.

\section{Simpulan}

Bedasarkan hasil penelitian yang telah dilakukan maka dapat disimpulkan untuk perencanaan penangkal petir pada gedung STTP adalah sebagai berikut :

1. Penangkal petir yang akan dipasang di gedung STTP adalah penangkal petir jenis Elektrostatis.

2. Jumlah finial yang tepasang adalah 1 unit.

3. Luas daerah ekivalen pada gedung STTP sebesar $15.827,49 \mathrm{~m}^{2}$.

4. Radius penangkal petir Elektrostik yang digunakan memiliki luas proteksi sebesar $31.400 \mathrm{~m}^{2}$.

5. Teriminasi udara dan konduktor penyalur menggunakan tembaga yang berukuran 35 $\mathrm{mm}^{2}$.

6. Di Riau mempunyai data hari guruh curah petir 218 dan dikelompokkan terjadi sambaran petir sangat tinggi.

\section{Daftar Pustaka}

[1] S. A. HUTAGAOL, "STUDI TENTANG SISTEM PENANGKAL PETIR PADA BTS ( BASE TRANSCEIVER STATION ) ( Aplikasi pada PT. Telkomsel - Banda Aceh )," Universitas Sumatera Utara, 2009.

[2] R. P. Ambarita, A. Syakur, and Yuningtyastuti, "Simulasi Penentuan Nilai Tahanan Pentanahan Menara Transmisi $150 \quad$ Kv Terhadap Backflashover Akibat Sambaran Petir Langsung," Transient, vol. 4, no. 4, 2015.

[3] F. A. Sinaga and Ansyori1, "Evaluasi Sistem Proyeksi Petir Menara Telekomunikasi PT Dayamitra Telekomunikasi (Telkom Group) Simpang Timbangan Indralaya," 
Mikrotiga, vol. 2, no. 1, pp. 11-15, 2015.

[4] Dachlan, H. S., Dhofir, M., \& Fernanda, V. (2012). Pengaruh Sudut Keruncingan Dan Diameter Finial Franklin Terhadap Distribusi Medan Listrik Dan Tingkat Tegangan Tembus. Jurnal EECCIS, 2(1), $1-10$.

[5] Atmam \& Situmeang, Usaha, 2015,
Perancangan Kinerja Penangkal Petir Menggunakan Metode Bola Gelinding pada Gedung Perpustakaan Universitas Lancang Kuning, Jurnal Sains, Teknologidan Industri, Volume 13 No. 1, pp. 130-135, ISSN : 2407-0939. Pekanbaru. 